\title{
Editorial
}

\section{Continous Professional Development And The Pharmaceutical Industry- Education Or Marketing?}

\author{
ARA Rashid
}

\section{Pharmaceutical Promotion}

It is perfectly understandable for the pharmaceutical industry to aggressively promote products on which huge sums of money have been invested at the developmental phase. The rigor of testing applied to modern pharmaceuticals has little parallel in other industry. Unlike most other products, pharmaceuticals have the potential to not only improve health but also to cause harm. As such the ethics of promotional activities in the marketing of pharmaceuticals has to be clearly defined. It should not influence doctors' autonomy in making decision although that has been previously showed to be insidiously influenced ${ }^{1}$.

Successful pharmaceutical companies realize that they must do more than just make attractive products. More often than not the 'packaging of a product' is more important than the product itself. To this end, promotional strategies are used to develop persuasive communication linkages between the company and its markets. Pharmaceutical promotion and advertising can influence not only the use of a product, but also our (doctors and public alike) belief on medicines. As promotion has the potential to change behaviour and because it is a major source of drug information for health professionals, the messages promoting pharmaceuticals should be factual, evidence-based, unambiguous and balanced. Many countries have already developed guidelines for promotional material ${ }^{2,3 .}$ There is also guideline tailored for specialist's society ${ }^{4}$ and guideline from Yale Medical School in an attempt to draw the line for its teaching faculty ${ }^{5}$. This was followed by other US medical schools. Skeptics may argue that it is not the existence of such guidelines but its adherence which is the problem. However experience from these US academic institutions which developed in house guidelines has been positive ${ }^{6}$.

\section{Promotion and Education}

One popular way to market a product is to promote it via educational activities. These can range from personalised delivery of educational materials by drug representatives to the doctor's office, company sponsored journal clubs, product presentations during lunch breaks, company sponsored Continuing Professional Development (CPD) programmes (ranging from one-off dinner talk to a full weekend workshop or seminar), company assisted conferences with industry sponsored symposia ( in the main programme to satellite symposia) as part of the programme and sponsoring of doctors (and pharmacists) to attend conferences. Indeed many companies will have their own dedicated "Educational Grants or Funds"for such activities. Some will utilize funds from the marketing and sales division because they see it as part and parcel of a common goal; that of promotion and successful marketing of their products

Ideally speaking, marketing should be more than just a promotional or selling effort to increase and satisfy demand for existing products and services. It should also seek to identify and respond to the needs, requirements, expectations and perception of its client; doctors and patients alike. It should lead to better overall performance of a doctor in managing their patients. This in turn should lead to better patient care and clinical outcome. However not all interactions between the medical profession and the pharmaceutical industry end up with positive patient outcomes. The emphasis tends to be more inclined to fulfilling the industry's objectives rather than the educational goals. Indeed a report from an extensive literature review found that doctors are affected by their interaction with pharmaceutical industry 7 .

There is evidence to show that doctors prescribing pattern is influenced after attending industry sponsored education programmes even when the programme is conducted in an academic environment governed by pre set ethical guidelines ${ }^{8}$. Another survey conducted with the use of self-reported questionnaire to psychiatry residents, interns and clerks

Corresponds to: Prof. Abdul Rashid Abdul Rahman, Centre for Graduate Studies, Research and Commercialization, Cyberjaya College of Medical Sciences, Cyberjaya, Malaysia. E-mail: Rashid@cybermed.edu.my 
showed that psychiatrist- in-training perceive little educational value in pharmaceutical representatives contact 9. However a more recent metanalysis showed there is no clear evidence that information prescribers get from pharmaceutical industry affect their prescribing habits positively or otherwise ${ }^{10 .}$

\section{Continuing Professional Development- Education or Promotion? \\ The very nature of medical practice demands life- long learning. The need for life long learning is never more pressing than in this era of "Information Technology" and "Patient Empowerment". The need to continuously develop oneself professionally has given rise to a concept the scope of which is much more than just attending the odd Continuing Medical Education (CME) lectures. Continuing Professional Development (CPD) includes a comprehensive approach in personal and professional development of a practitioner to meet the ever challenging demands of modern day medicine.}

Any development programme (CPD not an exception) requires adequate resources be it financial, infrastructural or human resources. Practically every other CPD activity is assisted either directly or indirectly by the pharmaceutical industry. In marketing sense, there is no better avenue than that provided by CPD activities. Not only is the logistics of addressing a wide audience of potential client achieved, the marketing strategy can be masqueraded by a neutral 'educational platform'. This can take the form of sponsoring the development of 'Evidenced Based Clinical Practice Guidelines (CPGs) to the plainly overt product launch in a desert island resort.

In between those extremes there are other types of activities in which pharmaceutical companies may be involved in. This include

$\mathrm{u}$ providing secretarial and financial support for activities as diverse as international scientific meetings, professional societies and patient support group,

$\mathrm{u}$ sponsoring local meetings of specialist groups which usually have an independent organiser or organising committee,

u hospital grand rounds and departmental scientific meeting.

$\mathrm{u}$ providing assistance in the form of subscription to journals and other independent educational materials u sponsoring awards and grants for academic excellence

While these activities usually have a clearly defined primary educational aim, they may be potentially open to the suspicion of unethical interaction between doctors and the pharmaceutical industry. Doctors involved in organising or participating in such activities need to have a high level of awareness of this risk. They should ensure they could meet any allegations of unethical behaviour, through avoiding any secrecy regarding the source and extent of sponsorship, and by ensuring that the provision of food or other attractions at these meetings is not on so lavish a scale as to cast doubt on the primary educational purpose of the meeting. The cost should not exceed that level which recipients might reasonably be expected to incur for themselves under similar circumstances. Sponsors of such activities must be prepared to accept that not all such activities will generate marketing spin-offs.

\section{Promotion and Education - Can They Co- Exist?}

Doctors and the pharmaceutical industry should work together to advance knowledge and enhance the availability of safe, effective, and fairly priced products for optimum patient care. Herein lays the common objective - the promotion of rational therapeutics. The anti thesis to this is when doctors collaborate with the industry in promoting irrational therapeutics. Rational therapeutics is by definition the proper use of treatment modalities which are efficacious, safe, convenient and cost-effective to patients. When we fail to educate doctors on how to make therapeutic decision rationally, not only may worthless treatment be applied, sometimes it is downright harmful11. Both doctors and the pharmaceutical industry are encouraged to work together to create an educational environment that improves practitioners and patients knowledge of pharmaceuticals and their proper use.

How can education and promotion co exist in a practical and ethical manner? To begin with a line must be drawn between what is ethical and what is unethical in terms of the general interaction between doctors and the pharmaceutical industry. There is currently a lack of guidelines issued to doctors in developing countries. In Malaysia such a guideline has been in existence developed by Ethics Committee of the Malaysian Medical Council and initiated by this author. Other Medical Councils in the region should 
also follow suit.

Among the important points to highlight is that doctors (often called key opinion leader or KOLs) should not participate in promotional activities that could in any way damage their public standing or reputation for independence of the profession in the eyes of:

$\mathrm{u}$ peers, colleagues and co-workers

$u$ the media

$\mathrm{u}$ patients and their relatives and

$u$ the general public.

Key opinion leaders have been viewed with skepticism by some ${ }^{12,13,14,15}$. Key opinion leaders are typically experts in their own field and most are also renowned researchers generating knowledge in relevant field of expertise. As clinician scientist, many will deny that their independence is influenced by the industry. Others have argued that they should remain independent and not work with industry. Opinion on this has been split ${ }^{16,17}$. It is however not that difficult to identify independent from heavily industry- influenced key opinion leaders ${ }^{18}$ Key opinion leaders themselves must ask some soul searching questions before accepting invitations to give lectures especially if it is industry sponsored. An important principle guiding ethical interaction between doctors and the industry is the dictum "would you be willing to have these arrangements generally known?"19. Another question which should always be asked, and be capable of comfortable answer is "can this presentation stand on its own without the financial support and influence of an outside body?"20. Indeed these questions should not only be asked by the key opinion leaders to themselves but also by the public. In other words what is needed as an antidote to concerns about unhealthy relationship between key opinion leaders and the industry is more transparency ${ }^{21 .}$

It is worth remembering that the pharmaceutical industry in mainly staffed by professionals who are trained pharmacists. Ethical guidelines should equally be applicable to members of this profession more so when they are industry based. This guideline is well spelt out by the American College of Clinical Pharmacist ${ }^{22}$ A closer scrutiny of these guidelines for doctors and pharmacist show strikingly similarities. As such if these are adhered to, unethical practices should be an exception rather than the rule. Problems arise when 'double standards" are applied by either party. It is encouraging to note that a survey among doctors across several specialties showed positive attitude towards guideline on this issue with willingness to comply with $i^{23}$ Even recent federal laws in the US (Anti-Kickback Statute and Federal Health Reform Law) do not prohibit doctors involvement with industry in research and education 24.

\section{Between Promotion and Education - Stick to the Evidence!}

The last few decades has seen an exponential increase in our understanding of disease pathogenesis and therapeutics. The science of epidemiology has also evolved from being restricted to the closet of public health to that of clinical medicine. Application of clinical epidemiology to daily clinical practice has given rise to a discipline of knowledge called 'Evidence Based Medicine' (EBM). Unfortunately there are at times too much lip service paid to EBM, when what is really required is for it to be practiced ${ }^{25,26 .}$

When there is good evidence that a particular drug is clinically beneficial than there should be no hesitation in its promotion. It can even be argued that once credible evidence has been generated, not applying it is unethical. The argument has always been how really credible is the evidence. Teaching doctors and medical students EBM is now a routine repertoire in many medical schools both at the post graduate and undergraduate levels. The right understanding of EBM will be an important pre requisite for doctors to navigate the sometimes confusing world of medical literature and continuing professional development programmes, many of which are directly or indirectly linked to the industry.. There is however one important

limitation with depending on EBM to help reconcile between promotion and education. The science of clinical epidemiology ( not to mention that of biostatistics !) which forms the foundation of EBM is not well taught and not well understood by many . This include doctors who contribute directly to educational programme as speakers. Such a vacuum in correct understanding of EBM will be readily capitalized by the industry in the promotion of certain products. In such an environment, promoting and marketing of products of dubious benefits to patients will take precedence over genuine education. Thus it is not the relationship between the industry and the 
medical fraternity which should be frown upon. The interaction though fraud with potential ethical minefields is symbiotic, provided the interest is focused not on the doctors or the industry's interest but that of the patients ${ }^{27}$ and is strictly evidenced based. In fact eliminating ethical interaction between the industry and doctors may hinder continuing professional developments of doctors which may be a disservice to patients ${ }^{28}$.

\section{Conclusion}

Educating medical students or doctors early in their training regarding the importance of professional ethics will promote and enhance their ethical behaviour as practicing doctors or specialists. Moreover, continuing education of doctors at all stages of professional development on ethical standards and con- duct will facilitate maintenance of high ethical standard throughout the profession. Experts who are invariably looked upon as key opinion leaders should maintain high ethical standards and act as role models, setting excellent examples for trainees and colleagues. To maintain the respect of patients and health care professionals as therapy expert, opinion leaders should always present therapeutic information in a fair, balanced, and evidenced based manner. Opinion leaders who allow themselves to be used as conduit for pharmaceutical manufacturers on a product when no credible evidence exist, are putting their reputations at stake. The industry in the meantime should avoid practicing double standards when it comes to the ethics of marketing, either via direct promotional activities or indirectly through educational programme.

\section{References}

1. Freeman JW, Kaatz B. The physician and the pharmaceutical detail main: an ethical analysis. $J$ Med Humanit Bioeth 1987;8(1) :34-39 http://dx.doi.org/10.1007/BF01119346 PMid:11649825

2. Roughead EE The Australian Pharmaceutical Manufacturers Association Code of Conduct: guiding the promotion of prescription medicines. Australian Prescriber 1999; 22 : 78-80

3. American College of Physicians. Physicians and the Pharmaceutical Industry Annals of Internal Medicine 1990; 112: 624-626.

4. Kahn NB Jr, Lichter AS; Council of Medical Specialty Societies; The new CMSS code for interactions with companies managing relationships to minimize conflicts. $J$ Vasc Surg $2011 ; 54(3): 34 \mathrm{~S}-40 \mathrm{~S}$ http://dx.doi.org/10.1016/j.jvs.2011.05.109 PMid:21872114

5. Coleman DL,Kazdin AE, Miller AE,Morrow JS, Udelsman M. Guidelines for interaction between clinical faculty and pharmaceutical industry: one medical school's approach : Acad Med 2006; $\quad \mathbf{8 1 ( 2 ) ; 1 5 4 - 1 6 0 ~}$ http://dx.doi.org/10.1097/00001888200602000-00011 PMid:16436576
6. Coleman DL. Establishing policies for the relationship between industry and clinician: lessons learned from two academic health centers . Acad Med 2008; 83(9):882-887 http://dx.doi.org/10. 1097/ACM.0b013e318181da0e PMid:18728449

7. Lechin J . Interactions between Physicians and the Pharmaceutical Industry: What does the Literature Say? Can Med Assoc J 1993; 149 : 1401-1407

8. Bowman MA, Pearle DL . Changes in drug prescribing patterns related to commercial company funding of continuing medical education . $J$ Contin Educ Health Prof. 1988; 8: 13-20 http://dx.doi.org/10.1002/chp.4750080104 PMid:10294441

9. Hodges B . Interactions with the Pharmceutical Industry: Experiences and Attitudes of Psychiatry Residents, Interns and Clerks. Can Med Assoc J 1995; 153: 553-559 (8)

10. Spurling GK, Mansfield PR, Montgomery BD, Lexchin J, Doust J, Othman N, Vitry AI. Information from pharmaceutical companies and the quality, quantity and cost of physicians' prescribing: as systemic review. PLoS Med 2010;7(10): e1000352 http://dx.doi.org/10. 1371/journal.pmed.1000352 PMid:20976098 PMCid:2957394 
11. Sackett DL, Haynes RB, Guyatt GH, Tugwell P. Deciding on the Best Therapy in Clinical Epidemiology . A Basic Science for Clinical Medicine 1991; Little, Brown and Company, Boston, USA PMCid:1453052

12. No Author Listed . Key Opinion Leaders: used as a marketing tool by drug companies. Prescrire Int 2012;21(128): 163-165

13. Adriane Fugh- Berman . Key Opinion Leaders : Thus are our medical meetings managed . BMJ 2008; 337 (7662): 128-129

14. Carl J Reynolds, Tom Yates and Robert Hughes. Key Opinion Leaders: Getting them when they are young. BMJ 2008; 337(7662): 129

15. Jelinek GA, Neate SL.The influemce of pharmaceutical industry in medicine. J Law Med 2009. 17(2):216-223 PMid:19998591

16 .Charlie Buckwell. Should drug industry work with key opinion leaders? Yes . BMJ 2008 . 336(7658):1404 http://dx.doi.org/10.1136/ bmj.39541.702870.59PMid:18566075 PMCid:2432129

17. Giovani A Fava. Should drug industry work with key opinion leaders? No . BMJ 2008. 336(7658):1405 http://dx.doi.org/10. 1136/bmj. 39541.731493.59 PMid:18566076 PMCid: 2432130

18. Alexander SD Spiers. Key Opinion Leaders : How to Spot One. BMJ 2008; 337 (7662): 129130.

19. The relationship between physicians and the pharmaceutical industry: a report of the Royal College of Physicians. $J$ R Coll of Physicians London 1989, 20: 235-42.

20. Position Paper of the American College of Physicians: Physicians and the Pharmaceutical
Industry. Annals of Internal Medicine 1990; 112 (8): 624-626. PMid:2327679

21. Ray Moynihan . Key opinion leaders : independent experts or drug representative in disguise? BMJ 2008 ; 336 (7658) :1402-1403 (9)

22. ACCP Position Paper . Pharmacists and Pharmaceutical Industry Guideline for Ethical Interaction . Pharmacotherapy 1993; 13 : 531533

23. Pinto SL, Lipowski E, Segal R, Kimberlin C,Algina J. Physicians Intent to comply with the American Medical Association's on gift from the pharmaceutical industry. $J$ Med Ethics 2007;33(6): 313-319 http://dx.doi.org/10. 1136/jme.2005.015529ＰMid:17526679 PMCid:2598281

24. Conn L, Venaglia L. Shining the light on physician-pharmaceutical and medical device industry financial relationship. $J$ Vasc Surg 2011;54 (3 suppl) : 22S-25S http://dx.doi.org/10. 1016/j.jvs.2011.05.106 PMid:21872111

25. Abdul Rashid A. Rahman . Evidence Based Medicine : Time to Practice Not Preach . CME Bulletin 1998; 1 : 1-2.

26. AR Abdul Rashid. Suboptimal of Chronic Diseases: Time to go back to Basic. Med J Malaysia 2008;63:185-187 PMid:19248686

27. Vashi NA, Latkowski JA. The ethics of medicalpharmaceutical relationship. Clin Dermatol 2012;30(2): 188-191 http://dx.doi.org/10. $1016 / \mathrm{j}$. clindermatol.2011.06.006 PMid:22330662

28. Wilson FS. Continuing medication education : ethical collaboration between sponsor and industry . Clin Orthop Relat Res 2003; 412:3337http://dx.doi.org/10.1097/01.blo. 000007 4409.99625.ca PMid:12838049 